\title{
LA LEY NATURAL \\ EN EL PENSAMIENTO DE JACQUES MARITAIN
}

\author{
MANUEL LÓPEZ-CASQUETE DE PRADO \\ Universidad Loyola Andalucía
}

\begin{abstract}
RESUMEN. La importancia de la obra del autor francés Jacques Maritain está fuera de toda duda. No sólo fue uno de los iniciadores del movimiento personalista, sino que influyó de forma decisiva en la Doctrina Social de la Iglesia desde Populorum progressio (1967) e inspiró el surgimiento de un gran número de partidos de inspiración cristiana. Uno de los mayores hitos de su carrera fue la participación en los trabajos preparatorios de la Declaración Universal de los Derechos Humanos, auspiciada por la ONU en 1948. Ese cometido ofreció a Maritain una ocasión privilegiada para debatir y hacer filosofía viva de sus tesis sobre la ley natural. En este artículo ofrecemos una revisión crítica del pensamiento iusnaturalista de Maritain y analizamos su participación en la Declaración de 1948, la cual avala la solidez de su elaboración filosófica.
\end{abstract}

PALABRAS CLAVE: Ley natural, Maritain, personalismo, iusnaturalismo, declaración universal.

\section{The natural law in the thought of Jacques Maritain}

ABSTRACT. The importance of the work of the French author Jacques Maritain is beyond doubt. He was one of the initiators of the personalist movement, and had a decisive influence on the Catholic Social Thought from Populorum Progressio (1967); he also inspired the emergence of a large number of Christian-inspired parties. One of the biggest highlights of his career was the participation in the preparatory works of the Universal Declaration of Human Rights, sponsored by the UN in 1948. That occasion offered him an extraordinary opportunity to discuss and make living philosophy of his thesis on natural law. This paper offers a critical review of Maritains's thinking on natural law and analyzes his participation in the UN Declaration, which guarantees the importance of his philosophical development. KEY WORDS: Natural law, Maritain, personalism, Universal Declaration, human rights.

\section{INTRODUCCIÓN}

Como afirma Contreras Aguirre (2009, pág. 19), la cuestión de la ley natural constituye tanto un paradigma como un enigma en la historia de la filosofía política y jurídica. H. Rommen (1950) plantea que la evolución del debate iusnaturalista se produce desde la lógica de un eterno retorno motivado por nuestra necesidad de fundamentar la vida social desde el punto de vista ético-jurídico. De este modo, continuamente regresamos a la reflexión sobre la ley natural para fundamentar los derechos humanos e indagar sobre la posibilidad de una justicia supra-positiva. Seguramente, uno de los mayores logros de la humanidad a este respecto es la Declaración Universal de los Derechos Humanos auspiciada por la ONU en 1948, en cuya preparación fue decisiva la presencia del filósofo francés Jacques Maritain. En este artículo nos planteamos analizar el planteamiento iusnaturalista del autor y el modo en el que se concretó su participación en la Declaración de 1948.

Sin entrar a fondo en el debate sobre la ley natural - lo cual desbordaría las posibilidades de este artículo-, consideramos conveniente situar a Maritain en 
el entramado de las distintas reflexiones iusnaturalistas, el cual ofrece una gran complejidad. Squella (1995, pp. 79-89) distingue hasta nueve corrientes del iusnaturalismo: realista (Aristóteles), racionalista (Grocio, Pufendorf), empirista (Hobbes, Locke), kantiano (Stammler), existencial (Maibofer), fenomenológico (Coing), personalista (Maritain), contractualista (Rawls) y marxista (Bloch).

No obstante, se puede extraer un núcleo común de las distintas posiciones iusnaturalistas: la idea de que en la naturaleza humana existe una carga normativa; o, con otras palabras, que en la descripción de lo humano (ontología) existe también una virtualidad de prescripción (deontología) (Contreras, 2009, pág. 22). Nos parece muy acertada la formulación que plantea a este respecto Javier Hervada:

"Cuando hablamos de derecho natural, de lo que estamos hablando es de que el hombre no se presenta ante los demás como un ser que pueda ser tratado a capricho, sino como un ser digno y exigente, portador de unos derechos que son inherentes a su propio ser. Más todavía; en la dignidad del hombre se contiene el fundamento de todo derecho, de manera que, fuera del respeto a lo que el hombre es y representa, no hay derecho, sino prepotencia e injusticia, aunque los instrumentos de estas tengan formas de ley» (Hervada, 1988, pág. 11).

En cambio, los detractores del iusnaturalismo denuncian como un error el paso del campo del ser al del deber ser, como ya planteara en el siglo XXII David Hume (1977, pp. 689-690). La respuesta iusnaturalista es que, ciertamente, ser y deber ser constituyen ámbitos gnoseológicos distintos, pero esto no excluye que del ser se desprendan consecuencias en el ámbito del deber ser.

El origen de la posición iusnaturalista nace con el surgimiento de la conciencia individual en el terreno del ethos, que marca el comienzo de la especulación en torno al problema ético de la justicia en el mundo griego precristiano (Contreras, 2009, pág. 27). La postura antitética del iusnaturalismo es el positivismo jurídico; también existen muy diversas posturas positivistas, aunque - del mismo modo- es posible extraer un núcleo común de todas ellas: no puede demostrarse la existencia de ninguna realidad normativa superior al derecho positivo que pudiéramos considerar natural. La mayor crítica que se objeta al positivismo es que articula su visión del derecho prescindiendo de la noción de valor. El propio Maritain afirma en Les droits de l'homme et la loi naturelle (1942) que sin la noción de valor no es posible construir una teoría de los derechos humanos.

La importancia del debate entre positivismo y iusnaturalismo radica en que apunta directamente a la propia naturaleza del derecho y al fundamento de su obligatoriedad.

Desde la matriz tomista en que se inserta su obra, Maritain realiza una firme defensa de la tradición iusnaturalista. Podemos considerar que el inicio de la reflexión iusnaturalista en Maritain está marcado por el planteamiento platónico de que existe un cierto orden inviolable que determina lo que las cosas son en su esencia. Con otras palabras, en las cosas existen ciertos requerimientos 
impuestos por su propia esencia. El fundamento de ese orden ideal es un espíritu separado y absoluto que constituye la ley eterna (Dios), del cual deriva toda norma.

El planteamiento de Maritain se sitúa sobre una comprensión material de los valores, la cual le aleja de éticas de corte procedimental como la kantiana. Esta crítica al formalismo kantiano está muy presente en muchos otros autores del movimiento personalista. Por ejemplo, en Rigobello:

«La axiología personalista se sitúa así en un contexto de apertura a la trascendencia, por lo que resulta imposible circunscribirla al ámbito de una “pura razón” de corte kantiano» (Rigobello, 1978, pág. 19).

Y también en Scheler:

«Nos enfrentamos entonces a la pregunta de si la ética formal, basada en la razón y la ley, no suprime a su vez la dignidad de la persona, a la que sitúa bajo el dominio de un Nomos impersonal, a cuya obediencia condiciona la única posibilidad de ser verdaderamente persona» (Scheller, 1944, en Rigobello, 1978, pág. 112).

Maritain ilustra su posición haciendo referencia al discurso de la Antígona de Sófocles, la cual justifica su derecho a desafiar la ley positiva de su tío Creón que le impedía enterrar a su hermano Polínices. Antígona invoca para ello la obediencia a leyes intemporales que no son de hoy ni de ayer, sino que viven en todos los tiempos y nadie sabe cuándo aparecieron.

La obra fundamental de Maritain en lo relativo a su reflexión iusnaturalista es Les droits de l'homme et la loi naturelle (1942), donde plantea que es imposible abordar una auténtica filosofía de la democracia y los derechos humanos sin atender en primer lugar a la ley natural, hoy desacreditada por el positivismo. A este respecto, González expresa la siguiente crítica:

"A lo largo de este siglo no han faltado intentos de poner en relación la doctrina clásica del derecho natural y la doctrina moderna de los derechos humanos. Entre ellos se cuentan los de Maritain [...]. En mi opinión, una síntesis teórica de ambas doctrinas es imposible, no sólo porque parten de premisas diferentes - de distintos conceptos del derecho-, sino porque ambas doctrinas gozan de un estatuto epistemológico diverso. A lo sumo podría hablarse de una síntesis práctica entre la doctrina clásica del derecho natural y los distintos Derechos Humanos, una síntesis orientada a la correcta aplicación de estos últimos. Precisamente a causa de las diferentes premisas y del diferente estatuto epistemológico, la palabra adecuada para designar la relación entre la doctrina clásica del derecho natural y la teoría moderna de los derechos humanos no sería tanto síntesis como complementariedad» (González, 1998, pág. 74).

No podemos compartir esta crítica; la autora circunscribe la virtualidad del derecho natural al estrecho ámbito de la correcta aplicación de los derechos humanos porque afirma que ambas doctrinas se basan en distintas concepciones del derecho y pertenecen a distintos niveles epistemológicos. Aunque esto fuera cierto, la autora no explica por qué no es posible fundamentar los derechos en 
las exigencias de la naturaleza humana desde la comprensión de que ambos constituyen dos niveles epistemológicos distintos, y por tanto, dos modos distintos de acercarse al derecho.

Una aproximación al encuadre de Maritain respecto a las distintas teorías iusnaturalistas es la elaborada por Viotto. Según éste, el filósofo parisino critica las posiciones de Grocio y del iusnaturalismo de la ilustración, que han referido el Derecho Natural sólo a la razón humana, alejándolo de la acción creadora de Dios (Viotto, 2010, pág. 30). Viotto esquematiza la historia del Derecho Natural afirmando que el iusnaturalismo estoico, el de Cicerón y el de la segunda escolástica, planteaban una idea de ley civil como referida a la ley natural, y ésta a la ley eterna. En un segundo momento, el iusnaturalismo ilustrado niega toda remisión a la ley eterna, separando legalidad de moralidad. Finalmente, el iuspositivismo reconoce legitimidad sólo al derecho positivo. En cambio, según Viotto, hoy se vuelve a hablar de Derecho Natural, aunque la fenomenología prevalente lo fundamenta sólo sobre la intersubjetividad, sin referencia alguna a elementos ontológicos. La posición de Maritain —continúa Viottoes radicalmente distinta, ya que, para él, no se puede fundamentar la ley natural sin referencia a la ley eterna. El esfuerzo del autor se orienta a actualizar los argumentos tomistas relativos a la ley natural afirmando que la humanidad continúa avanzando en su conocimiento a través de la historia.

Para completar el esquema de Viotto, es preciso profundizar en la crisis iusnaturalista acaecida con la modernidad. A pesar de las críticas de Hume, la ley natural permaneció en el centro de la filosofía moral hasta bien entrado el siglo XIX, cuando la filosofía moral kantiana empezó a ser el punto de referencia generalmente aceptado (González, 2008, pág. 4). En Kant, la ley natural en sentido clásico, cognoscible por inclinación, no juega ningún papel, ya que establece una estricta separación entre todo elemento empírico y la ley moral:

«Dos cosas llenan el ánimo de admiración y respeto, siempre nuevos y crecientes, cuanto con más frecuencia y aplicación se ocupa de ellas la reflexión: el cielo estrellado sobre mí y la ley moral en mí» (Kant, 1977, pág. 171).

Aunque Kant utiliza el término ley natural con profusión, lo hace en sentido moderno, científico y newtoniano, como ley de causalidad universal.

En la reflexión del propio Maritain sobre la elaboración histórica de la ley natural, el autor plantea que la modernidad supuso un ataque frontal al iusnaturalismo y el inicio de la profunda crisis en que aún se encuentra inmerso. Con el racionalismo, la voluntad y la libertad ocupan el lugar de fuente de la ley natural. Se abre así un proceso en el que los derechos de los individuos pasan a ser derechos absolutos (los derechos de un dios, dice Maritain). Así, en Kant y en Rousseau, la persona sólo debe estar sometida a la ley que se da a sí mismo. Y al contrario, toda norma que emanase de la naturaleza sería considerada heterónoma, y por tanto destructora de su autonomía y su dignidad, ya que los derechos divinos del hombre rechazarían toda limitación.

Para Maritain, la gravedad de esa construcción estriba en que no sólo reivindica los derechos propios a expensas de los derechos de los demás, sino que 
además, al carecer de todo referente universal, conduce al escepticismo como expresión de la crisis de nuestra civilización. Frente a esto, Maritain reivindica una idea real de ley natural que responda a los requerimientos de la naturaleza creada por Dios. En palabras de Possenti,

[Para Maritain], «en la doctrina kantiana del imperativo categórico, soy llevado no sólo a obedecer a una ley general y universal, sino que además me anulo éticamente como persona singular ante la generalidad y universalidad de la ley» (Possenti, 2003, pág. 74).

Sin embargo, según Maritain, la sociedad de su tiempo sigue manteniendo al margen toda noción que remita a la ley natural. Si en la Edad Media existía una misma concepción iusnaturalista, la sociedad del siglo XX está sometida a grandes discusiones, fruto de una enorme fragmentación espiritual. Maritain reivindica la necesidad de recuperar la atención a lo que el ser humano es según su propia naturaleza, y diseñar desde ahí el entorno social, económico e institucional de que debemos dotarnos: es preciso, por tanto, volver al Derecho Natural (Maritain, 1942).

Debemos subrayar que esta necesidad manifestada por Maritain de volver al Derecho Natural se plantea en 1942, en plena segunda guerra mundial, con la obra Les droits de l'homme et la loi naturelle. En esos años, el debate iusnaturalista se intensificó en un intento de recuperar criterios morales universales más allá de los contextos éticos particulares. El holocausto nazi había supuesto una grave ofensa a la dignidad y la libertad de la persona; en esta situación, de nuevo empezó a proponerse la ley natural como base para fundamentar los derechos humanos. Ahí se incardina el trabajo y la reflexión sobre la ley natural de Maritain, en el seno de las teorías iusnaturalistas tomistas contemporáneas (González, 2008, pág. 4). Desde las urgencias propias de este momento histórico, Jacques Maritain abordó de modo creativo algunos aspectos del tomismo clásico, incluyendo el tema de la ley natural (Burgos, 2006, pp. 46-47).

\section{Ontología y EPISTEMOLOGÍA}

El iusnaturalismo tomista se enraíza en una concepción ontológica según la cual el conocimiento del ser se corresponde con el conocimiento del deber ser. Partiendo de ella, la reflexión iusnaturalista debe también responder a la pregunta sobre cómo podemos conocer la ley natural. El abordaje de Maritain a la cuestión, esencialmente contenido en Les droits de l'homme et la loi naturelle (1942), también se plantea desde esta doble perspectiva, ontológica y gnoseológica:

- Desde el punto de vista ontológico, la ley natural, heredada del pensamiento clásico cristiano, se basa en la existencia de una misma naturaleza común a todo hombre, fruto de la razón creadora de Dios, inmutable y comprensible por la razón. Esto confiere a toda la comunidad humana la orientación a los mismos fines, hacia los cuales debe acomodar su comportamiento: 
«Existe, en virtud de la misma naturaleza humana, un orden o una disposición que la razón humana puede descubrir, y según la cual la voluntad humana debe actuar para estar en concordancia con los fines necesarios del ser humano. La ley no escrita o el derecho natural no es otra cosa que esto » (Maritain, 1942, pág. 658).

- Desde el punto de vista gnoseológico, el fundamento de la ley natural (no sólo en Maritain, sino en toda la línea de pensamiento iusnaturalista en la que él se sitúa) deriva de la sabiduría creadora de Dios. Sin embargo, no es necesario creer en Dios para conocerla y respetarla: basta con conocer la naturaleza humana. Con otras palabras, el conocimiento de la ley natural no deriva de la fe, ni siquiera de la razón, sino fundamentalmente de la inclinación de nuestra naturaleza, lo cual marca un camino oscuro y asistemático. En palabras de V. Possenti, dicho conocimiento por inclinación

«No es un conocimiento claro de conceptos y juicios conceptuales; es un conocimiento oscuro, asistemático, vital, que procede por inclinación experiencial o por "connaturalidad" y en el cual el intelecto, para formar un juicio, consulta y escucha esa especie de canto producido en el sujeto por la vibración de su inclinación interior» (Possenti, 2003, pág. 138).

Por este motivo, el conocimiento de la ley natural ha ido avanzando con la historia y continúa desarrollándose como fruto de la evolución y el progreso humano. De ahí que la captación que hace cada cultura y cada época de la ley natural sea también distinta:

«Así, la ley natural no cambia porque la naturaleza humana tampoco cambia. Lo que cambia es el conocimiento de la naturaleza humana — para mejor o para peor-»(Denney, 2013).

De este planteamiento gnoseológico se derivan importantes consecuencias: puesto que la ley natural no deriva de la fe, sino de la inclinación común de nuestra naturaleza humana, puede ser conocida y compartida por todos los seres humanos. En palabras de Viotto, sobre la base del reconocimiento práctico de esta ley natural, aun partiendo de diversas motivaciones teóricas, se puede articular un diálogo que supere tanto el relativismo como el fundamentalismo (Viotto, 2010, pág. 30).

Esta inclinación, que McCauliff entiende como intuición, es clave para entender la concepción iusnaturalista de Maritain:

«La intuición en forma de inclinación humana o connaturalidad jugó un importante papel en la filosofía de la ley natural de Maritain y en su percepción de cómo entramos en diálogo con los demás sobre la base de acuerdos en los principios básicos» (McCauliff, 2009, pág. 437).

Según McCool, la importancia de la intuición en el sistema de Maritain proviene de su influencia bergsoniana, aunque el uso de dicha intuición en Maritain quedó claramente transformado tras su lectura de Santo Tomás. Si en Bergson la intuición permanece separada de la función intelectual, tras iniciarse en el estudio de las obras tomistas, Maritain asumirá que sólo hay 
conocimiento cuando la inteligencia permanece activa. Sin embargo, el intelecto puede conocer a través de la intuición lo esencial de la realidad de un modo mucho más profundo que el discurso racional (McCool, 1994, pág. 77).

Para McCauliff, la intuición en Maritain es preconceptual. Un preconcepto es un concepto no formulado ni verbalizado; sobre dicha intuición, la comprensión humana debe realizar un proceso de actualización mediante el racionamiento discursivo, la investigación, el análisis, la elaboración de teorías y la verificación. De este modo, los preceptos de la ley natural son cognoscibles inmediatamente por inclinación, pero no pueden ser demostrados porque para ello precisan de la razón, que proporciona un conocimiento mediato (McCauliff, 2009, pág. 445).

Respecto al concepto de intuición o inclinación en Maritain, McCauliff plantea que las más recientes investigaciones empíricas sobre el sentido moral en los campos de la psicología, la neurociencia y la neurobiología confirman que la aproximación de Maritain al problema del conocimiento de la ley natural es acertada:

«Estos hallazgos ofrecen evidencia empírica a la teoría de Maritain de que la persona primero enfoca los principios de justicia a través de la intuición, y justifica sus aprehensiones después» (MacCauliff, 2009, pág. 449).

Uno de los autores que critica el planteamiento gnoseológico de la ley natural en Maritain es Juan Manuel Burgos. Según este autor, no parece acertada la afirmación de Maritain de que su teoría del conocimiento por inclinación sea de raíz estrictamente tomista. Burgos plantea que, aunque Santo Tomás manifiesta la importancia del papel de la inclinación en el conocimiento humano, Maritain se separa de su maestro al rechazar la primacía del conocimiento conceptual de la ley natural. La gravedad de este planteamiento estriba en que, si el conocimiento de la ley natural se produce mediante la inclinación personal, se pone en cuestión una de sus características esenciales: su universalidad. Burgos considera que sólo el esfuerzo de la elaboración conceptual puede eliminar los aspectos personales y mantener los generales, válidos para todo hombre (Burgos, 2006, pp. 116-117). Según Burgos, parece que Maritain haya querido evitar los excesos del racionalismo y se haya cerrado excesivamente al concepto (Burgos, 2006, pág. 118).

No podemos estar de acuerdo con esta crítica por dos motivos:

- El primero, porque se diría que Burgos no está considerando oportunamente el peso que Santo Tomás otorga a la inclinación natural como vía epistemológica de la ley natural (genéricamente entendido como conocimiento del bonum). Así, en la Summa theologiae:

«Hay en el hombre una inclinación al bien correspondiente a la naturaleza racional, que es la suya propia, como es, por ejemplo, la inclinación natural a buscar la verdad acerca de Dios y a vivir en sociedad» (Aquino, 2001, tomo II, pág. 733). 
Esta inclinatio ad bonum nos parece central en la gnoseología tomista de la ley natural, por cuanto que el Aquinate la considera íntimamente esencial al ser humano (quae est sibi propria); tal centralidad ostenta en el sistema tomista, que es comparada con la propia inclinación de la persona al conocimiento de Dios. Así lo entiende también Wechsung, que cita a este respecto la Summa contra gentiles (libro 3, capítulo 16): Todo está ordenado a un solo fin que es Dios.

Wechsung interpreta esta cita desde la idea de que en todos los entes creados hay una inclinación por la cual se dirigen de modo necesario al fin conveniente según la propia naturaleza. En consecuencia, las cosas creadas están gobernadas por Dios mediante las inclinaciones naturales, y así se someten al orden de la ley eterna (Wechsung, 2003, pág. 4). Y en otro lugar: a la ley natural pertenecen las cosas a las que el hombre se inclina según su naturaleza (Wechsung, 2003, pág. 9).

Aunque discrepamos con Wechsung en la necesariedad de la dirección a Dios en el comportamiento de todo lo creado - lo cual excluiría la libre determinación humana-, estamos de acuerdo en su consideración de la importancia de la inclinación natural en la epistemología tomista.

Aún más clara nos parece a este respecto la siguiente cita de la Suma teológica, que no deja lugar a ninguna duda:

«Por lo mismo, hay también en ella [la criatura racional] una participación de la razón eterna en virtud de la cual se encuentra naturalmente inclinada a los actos y fines debidos. Y esta participación de la ley eterna en la criatura racional es lo que se llama ley natural» (Aquino, 2001, tomo II, pág. 736).

Ciertamente, en Santo Tomás la inclinación natural no es una vía cognoscitiva separada de la razón y de la voluntad, sino que se articula y armoniza con ella en forma de una inclinación racional como participación humana en la razón creadora (del mismo modo que en el orden práctico la inclinación se armoniza con la voluntad). Esta orientación gnoseológica es la misma que plantea la Comisión Teológica Internacional al conceptuar la ley natural:

«El concepto de ley natural supone la idea de que la naturaleza es portadora de un mensaje ético que se constituye en norma moral cuando la razón humana lo actualiza» (Comisión teológica internacional, 2009, nº 69).

En cualquier caso, la centralidad de la inclinación nos parece absolutamente incuestionable en el planteamiento gnoseológico tomista de la ley natural. En dicho planteamiento (Aquino, 2001, tomo II, pp. 757 y ss.) se produce una primera captación por inclinación de la ley natural de la que derivan preceptos primarios de contenido muy general (los relativos a la conservación de la vida, la reproducción y el impulso al conocimiento de la verdad). De estos preceptos, y por obra de la razón discursiva, la persona puede acceder a preceptos secundarios de contenido más específico (Irrazábal, 2011, pág. 15). Como el propio Aquinate especifica, a medida que se desciende a principios más particulares, aumenta la indeterminación (Aquino, 2001, tomo II, pág. 760 y ss.). Este descenso a concreciones particulares es descrito por Maritain cuando muestra las 
diferencias entre derecho natural, derecho de gentes y derecho positivo, en el que ilustra claramente cómo se va incrementando el grado de contingencia y mutabilidad a medida que aumenta el grado de concreción. Del mismo modo, y a nivel epistemológico, a medida que se desciende en el grado de concreción, es mayor el peso de la elaboración racional-discursiva historizada y menor el de la inclinación ${ }^{1}$. En la misma línea, para Sweet,

«Seguramene es más plausible sostener que tales preceptos [secundarios] se derivan de los primeros principios de la ley natural por vía de inferencia y, en consecuencia, son mejor entendidos como parte de lo que él [Santo Tomás] llama derecho de gentes o ley común de las civilizaciones» (Sweet, 1998, pág. 147).

En conclusión, y en contra del argumento de Burgos, sostenemos que Santo Tomás otorga cierta primacía epistemológica a la inclinación, la cual debe armonizarse posteriormente con las exigencias de la razón para interpretar, dotar de sentido y — sobre todo- concretar la captación intuitiva. Como afirma Irrazábal,

«Este conocimiento está mediado, por una parte, por las inclinaciones de la naturaleza, expresión de la sabiduría creadora, y por otra, por la luz de la razón humana, que interpreta y que es ella misma una participación creada en la luz de la inteligencia divina» (Irrazábal, 2011, pág. 18).

- Nuestra segunda objeción al planteamiento de Burgos es la siguiente: no hay por qué suponer que la inclinación no pueda obedecer a un mismo impulso natural humano, y que, en consecuencia, las captaciones que ofrece puedan ser compartidas por todos los hombres (p.e., en la regla de oro tomista: hacer el bien y evitar el mal). Con otras palabras, no está claro que la inclinación excluya la universalidad. No ignoramos que se trata de un problema complejo; en palabras de Sweet, reivindicar como ley natural aquello a lo que uno se siente inclinado, posibilita la incursión en un peligroso intuicionismo moral:

«Reclamar que se puede conocer si una nueva inclinación es natural, simplemente determinando si el conocimiento de ella es obtenido por connaturalidad, es algo peligrosamente cercano al intuicionismo moral» (Sweet, 1998, pág. 148).

En nuestra opinión, y para evitar este problema, la concepción epistemológica mariteniana-tomista de la ley natural debe ser completada con el debate público, en la línea de los postulados ofrecidos por las éticas dialógicas (por ejemplo, las propuestas por Apel y Habermas y por Adela Cortina). Aunque Maritain no hace mención expresa de ello, su intervención en la Declaración de los Derechos Humanos de la ONU de 1948 es muestra de cómo el debate público (en el marco de un contexto privilegiado como el de la ONU) y la epistemología

1 En cualquier caso, este planteamiento no está exento de problemas especulativos, en particular en lo referente a la prioridad o jerarquía de los distintos preceptos en el conjunto de la ley natural. Sobre esto, Sweet (1998). 
intuitiva de la inclinación pueden armonizarse de un modo incomparablemente fértil en el propósito de hallar un sustrato ético-práctico común.

\section{La participación de Jacoues Maritain en la Declaración de los Derechos Humanos de LA ONU DE 1948}

Nuestra opinión, en contra de las críticas manifestadas en el epígrafe anterior, es que la elaboración epistemológica de raíz tomista que ofrece Maritain, aunque no esté exenta de ciertas dificultades especulativas, es una de las más brillantes y genuinas aportaciones del filósofo francés. El mejor aval de esta elaboración se desprende de la participación de Maritain en los trabajos preparatorios de la Declaración de los Derechos Humanos de la ONU de 1948, que muestran de modo fehaciente que «J. Maritain había tomado otro camino, recurriendo a la doctrina tomista de las verdades prácticas contenida en la Suma Teológica, I-II, q.94, a.2, según la cual, en los primeros principios prácticos captados intuitivamente la razón no puede equivocarse; sí, en cambio, puede errar en la justificación racional» (Irrazábal, 2011, pág. 25). Nos resulta evidente la coherencia del planteamiento gnoseológico de Maritain con el de Santo Tomás.

La participación de Maritain en la Declaración de 1948 no sólo conjura las mencionadas críticas, sino que, sobre todo, permite entender la vigencia y el acierto de su planteamiento gnoseológico relativo a la ley natural.

Para evitar un malentendido que se comete a menudo, hay que decir que Maritain no participó en ninguna de las comisiones de redacción de la Declaración, las cuales fueron encargadas al Consejo Económico y Social, sino en los informes preparatorios que elaboró la UNESCO por encargo de la ONU.

En 1947, la UNESCO elaboró una encuesta sobre los problemas teóricos que planteaban los trabajos preparatorios y la dirigió a personalidades del mundo entero, incluyendo a Jacques Maritain, quien respondió en el mes de junio del mismo año. Unos meses más tarde, en la segunda Conferencia General de la UNESCO, su respuesta alcanzó una gran importancia. Maritain era el jefe de la delegación francesa, y tuvo que presidir la sesión inaugural de la Conferencia el día 6 de noviembre. Su discurso de apertura marcaría de modo decisivo el signo de la conferencia (Mougel, 1998, pp. 13-14). Como recuerda Seydoux,

«Los delegados de las naciones representadas le escuchaban en silencio, cautivados. Sobre la escena internacional, que no era rica en personalidades fuertes, un hombre nuevo aparecía: Jacques Maritain [...]. Su llamada a todos los hombres de buena voluntad era una respuesta a un texto de Julian Huxley titulado L'Unesco, ses buts et sa philosophie. Tras la intervención magistral de Jacques Maritain, Huxley cesó de invocar su línea de conducta, puramente materialista. Empezó a hablar de cooperación entre los hombres, de tareas prácticas a desarrollar. La conversión inspirada por el jefe de la delegación francesa fue, en definitiva, aceptada por todos» (Seydoux, 1984, pág. 27). 
Aunque Maritain parte de un planteamiento filosófico netamente distinto al de Huxley, en su discurso no plantea un duelo especulativo con él. Al contrario, su objetivo es mostrar que, aunque la humanidad se encuentra dividida sobre la base de desacuerdos intelectuales, es posible la cooperación práctica. Una cooperación que no implica compartir una misma concepción del mundo, el hombre y el conocimiento, sino tan sólo la afirmación de un mismo cuadro de convicciones prácticas, el cuadro moral del mundo civilizado. Con otras palabras, el discurso de Maritain defendía firmemente la idea de una comunidad de pensamiento práctico y de convicciones comunes relativas a la acción entre hombres de culturas distintas e incluso de ideologías antagonistas.

Esta idea de cooperación, tolerancia y posibilidad de encuentro en la común naturaleza humana permitió a la UNESCO avanzar evitando las trampas de las posiciones sostenidas por Julian Huxley, entonces Director General, y otorgó a Maritain un rol preponderante en la Conferencia de México. En efecto, fue el propio Huxley (mostrando en esto altura de miras y nobleza intelectual) quien encargó personalmente a Maritain la redacción de la introducción del informe que la UNESCO enviaría a la Comisión de Derechos Humanos de la ONU. Por su parte, René Cassin, uno de los principales redactores de la Declaración, reconocería públicamente la influencia decisiva del discurso de México y del informe de Maritain en una sesión de la UNESCO:

«Por su parte, René Cassin, quien fuera uno de los principales redactores de la Declaración, hacía referencia a estos documentos y al discurso de México, reconociendo públicamente en una sesión de la Unesco en la que Maritain recibió una memorable ovación, que la Declaración de 1948 había sido orientada siguiendo la inspiración de Jacques Maritain, en un espíritu de idealismo práctico »(Mougel, 1988, pp. 13-14).

En referencia a este discurso, Papini plantea que, considerando el año en que se desarrollaba, probablemente Maritain pensaba también que no era imposible una colaboración con los comunistas en un plano puramente práctico (Papini, 2011, pág. 235).

Siguiendo aún a Papini, la posición de Maritain en la Declaración de 1948 resulta hoy de gran actualidad, especialmente por la fuerte reivindicación de los derechos culturales:

«En una posición similar a la de Maritain, pero naturalmente con ciertas diferencias, encontramos a John Rawls con su teoría del consenso por intersección (overlapping consensus), a Martha Nussbaum y su teoría sobre las capacidades y también a Amartya Sen. En una posición distinta (no tanto en la crítica al neoliberalismo) están los communitarians norteamericanos a partir de Ch. Taylor, quienes no se limitan a defender el reconocimiento de los derechos colectivos de una comunidad cultural (entendida como principal o única posibilidad del individuo de realizarse), sino que dudan de la posibilidad de entendimiento sobre valores universales»(Papini, 2011, pág. 236).

Después de la publicación de la Declaración, el propio Maritain fue comisionado por la UNESCO para reunir y sistematizar las respuestas que ésta había 
suscitado. En la introducción al volumen que recoge estas respuestas, plantea que la declaración de 1948 constituye un acuerdo práctico entre hombres con posiciones teóricas opuestas, lo cual supone un gran progreso para la unificación mundial. También advierte que en el volumen están representadas muy diversas escuelas y tradiciones de pensamiento, incluso contrarias. Y, sin embargo, sorprende la unanimidad en la aceptación de esos derechos. Dicho consenso - continúa el autor - responde a un mismo sustrato ético conocido por inclinación y compartido por todos los hombres con anterioridad a la reflexión intelectual. Esto permite un progreso moral de la humanidad como desarrollo práctico al margen de sistemas teóricos. Dicha concordancia se produce

«...no sobre la base de un pensamiento especulativo común, pero sí sobre la comunidad de un pensamiento práctico; no sobre la afirmación de idéntico concepto del mundo, del hombre y del conocimiento, pero sí sobre la afirmación de un mismo conjunto de convicciones respecto a la acción» (Maritain, 1948, pág. 21).

Aunque Maritain no lo dijera expresamente en su discurso ante la UNESCO de 1947, el punto nuclear de su intervención se basa en la profunda y firme convicción de que los aspectos sustantivos de acuerdo entre las personas dependen de una percepción intuitiva de la ley natural, que nos inclina hacia la virtud práctica en función de nuestra común identidad humana. En cambio, nuestras justificaciones filosóficas tienen lugar a posteriori como elaboración del razonamiento discursivo, y a menudo sirven para crear divisiones en la comunidad humana (McCauliff, 2009, pág. 472). Esta perspectiva de acuerdo práctico en la Declaración de 1948 no significa que Maritain no esté interesado en abordar una sólida fundamentación teórica de los derechos. Partiendo de la ley natural y su correlación de derechos y deberes, Maritain afronta una prolija elaboración de la cuestión en la que detalla los deberes sociales respecto al bien común que deben ser satisfechos prioritariamente.

Según McCauliff, la noción europea de ley como contrato social descansa en la necesidad de cumplimiento de una prestación para poder exigir la correspondiente contraprestación a la otra parte. En términos de derechos y obligaciones sociopolíticos, el énfasis en la obligación derivada de la ley natural requiere que el ser humano reciba sus derechos en el contexto del rol social de cada persona. Maritain, en cambio, inspirándose en la Declaración de Independencia de EE.UU., abstrae al ser humano de su contexto social para vincular los derechos a la mera existencia de la persona:

[Maritain] «toma en consideración la declaración Americana de independencia, y abstrae al ser humano del contexto de la ley natural para fundamentar los derechos sobre el mero hecho de la existencia humana» (McCauliff, 2009, pág. 466).

Maritain insiste, por tanto, en hacer derivar los derechos de la naturaleza humana, lo cual les confiere la condición de inalienables, dado que nadie puede perder dicha naturaleza humana. Esto no implica rechazar toda limitación a 
los derechos naturales, ya que se orientan hacia el bien común y pueden ser modulados por éste (McCauliff, 2009, pág. 469).

De esta reflexión surge una importante distinción en el sistema de Maritain: posesión y ejercicio de los derechos. Decíamos anteriormente que los principios universales derivados de la ley natural pueden ser concretados en distintas reglas, costumbres y leyes. De este modo, la posesión de los derechos humanos resulta inalienable por basarse en la propia naturaleza del hombre. Sin embargo, el ejercicio práctico de esos derechos no es ilimitado, sino que puede y debe ser modulado en función del bien común. Esto conduce a fuertes discrepancias entre los hombres respecto a la determinación de esas restricciones y la primacía de unos u otros, lo cual da lugar a filosofías políticas incompatibles. Así, el liberalismo da primacía a la libertad de apropiación y al derecho de propiedad (o bien total), el comunismo da primacía a la subordinación de los bienes al colectivo social (o bien colectivo) y el personalismo da primacía a la dignidad humana y a la búsqueda del bien común. Para Maritain, evidentemente, el tercero expresa una comprensión más acorde a la naturaleza humana.

Esta correspondencia entre ley natural y bien común fue muy bien acogida por MacIntyre, quien entiende el bien común como aquél hacia el que se inclina la persona cuando funciona con normalidad y se desarrolla como tal:

«Los preceptos de la ley natural nos orientan hacia el bien común [...]. Mi propio bien sólo puede ser alcanzado en y a través de la consecución del bien común. Y es al bien común hacia donde nos inclinamos cuando funcionamos de forma normal y nos desarrollamos como debemos» (McIntyre, 2000, pp. 108-109).

La participación de Maritain en los trabajos previos a la Declaración de los Derechos Humanos también propició — según McCauliff_ - una clara transformación en su comprensión de la intuición como vía de conocimiento de la ley natural. Así, a partir de 1948, el filósofo francés matiza su comprensión del problema epistemológico de la ley natural, y plantea que éste se articula sobre una intuición personal:

«De este modo, Maritain toma los planteamientos tomistas de la ley natural, enraizados en la razón como inspiradora del sentido moral, y los eleva a un nuevo nivel moviendo el foco desde el sistema de la ley natural a la aprehensión individual de ella» (McCauliff, 2009, pág. 440).

Después de esta experiencia, Maritain situará dicha intuición personal sobre lo que es correcto en el núcleo de las posibilidades humanas de cooperación y acuerdo. En consecuencia, su concepción epistemológica relativa a la ley natural se afirma y asienta definitivamente desde la idea de intuición personal. Esta posibilidad de cooperación sobre una base sustantiva y sin necesidad de acuerdo filosófico es considerada por algunos autores como una de sus propuestas más útiles (McCauliff, 2009, pág. 441). Según McCauliff, Maritain da al concepto de intuición un fuerte impulso como categoría actual; si en la concepción tomista la intuición permanece circunscrita al ámbito de las virtudes morales, Maritain lleva el concepto mucho más allá, elevándolo a la consideración de 
aspecto nuclear en todo diálogo humano (McCauliff, 2009, pág. 443). De fondo, en la propuesta de Maritain está contenida una idea de respeto sagrado al otro como núcleo esencial de los derechos reconocidos en la Declaración.

En lo relativo a la tensión entre inclinación preconceptual y razón discursiva, la tradición de pensamiento en la que se sitúa Maritain ofrece un planteamiento epistemológico que armoniza «el significado propio de los dinamismos naturales pre-racionales, y por otro, la función indispensable de la razón, encargada de integrar y jerarquizar dichas inclinaciones en la unidad de la persona y al servicio de su realización» (Irrazábal, 2011, pág. 25).

Según Parellada, este acuerdo práctico defendido por Maritain influiría notablemente en el sistema de Rawls, para quien los distintos pueblos y doctrinas razonables "pueden estar de acuerdo en el contenido central de los derechos humanos sin compartir las razones para abrazarlos» (Parellada, 2010, pág. 803). No obstante, muchos autores —incluido el propio Parellada- se muestran contrarios a esta perspectiva por cuanto que supone una dejación de las funciones que son propias e inherentes a la filosofía.

Michael Novak, en contra de esta postura, valora decididamente esta disposición al acuerdo práctico que Maritain alentó en 1948:

«Son importantes, e históricamente raras, las disciplinas sociales que aceptan estar de acuerdo sobre el desacuerdo; cooperar con personas cuyos puntos de vista no compartimos; comprometerse por causa de la cooperación, incluso cuando no se renuncia a los propios principios orientados hacia una meta. Parece tan natural sostener que "si usted no está conmigo ciento por ciento, usted está contra mí”, que muchas personas creen casi impensable que se pueda llegar en la práctica a una acción cooperativa. El espíritu de compromiso práctico les parece un abandono de los principios, más que un juicio, lo que de hecho es, en el sentido de que en este mundo las sociedades deben avanzar con pasos prácticos hacia la justicia próxima, en tanto que cualquier intento de obtener la justicia absoluta es inevitablemente criminal. La enseñanza social católica debe aprender a destacar esta virtud crucial de la democracia práctica» (Novak, 1983, pág. 15).

Nos adherimos totalmente a este planteamiento; a pesar de las mencionadas objeciones, no podemos dejar de afirmar que la Declaración de 1948 supuso un avance en la concreción universal de los derechos humanos, y que no por ello la filosofía (ni tampoco Maritain) deben abandonar ni abandonan el propósito de hallar una sólida fundamentación teórica de los derechos.

Para MacIntyre, con Maritain queda cerrado el tema de la captación de la ley natural. Lo que más despierta el entusiasmo de MacIntyre es que, a diferencia de otros autores, Maritain considera que la captación de la ley natural es asequible a toda persona, sin limitar sus posibilidades de comprensión a cualquier tipo de élite intelectual. Esta impresión de MacIntyre resulta evidente si leemos algunos pasajes de Natural law. Reflections on theory and practise (Maritain, 2001). En esta obra, Maritain plantea que un filósofo moral puede conocer todo sobre la virtud y, aún así, no ser un hombre virtuoso. En cambio, 
un hombre virtuoso puede ignorar todo concepto de filosofía moral pero conocerlo todo sobre las virtudes por connaturalidad.

\section{Conclusiones}

El planteamiento gnoseológico de Maritain respecto a la ley natural ofrece aspectos positivos y negativos. En lo positivo, ofrece una visión flexible de la ley natural, y da carta de naturaleza a las intuiciones morales, que con tanta frecuencia son excluidas por las distintas construcciones teóricas de la justicia. En el lado negativo, la intuición es amorfa y difícil de aplicar, especialmente dadas las grandes diferencias culturales de las distintas sociedades. No es posible, por tanto, ignorar las dificultades especulativas que plantea un concepto tan ambiguo y difuso como el de inclinación. El propio Maritain menciona que esta inclinación por connaturalidad debe abrirse paso a través del mundo inconsciente e instintivo descrito por Freud (Maritain, 1950, pp. 63-64), y que algunas inclinaciones no siempre han estado presentes en la evolución humana, sino que han permanecido ocultas durante gran parte de su historia a consecuencia de determinadas convicciones culturales.

Las dificultades de este planteamiento son evidentes. En palabras de Sweet:

«Dado que no poseemos aún una comprensión completa de la naturaleza humana y de lo que es esencial en ella, ¿cómo sabemos que semejantes inclinaciones son fundamentales y racionales, y cómo podemos decir que dichas inclinaciones tienen prioridad sobre otras "más primitivas”?»(Sweet, 1998, pp. 63-64).

La solución que Maritain aporta en Les droits de l'homme et la loi naturelle (Maritain, 1942) es que la ley natural obliga si es conocida (el equivalente al sufficenter promulgata en la célebre definición tomista de ley positiva) y está encarnada en la herencia general de la humanidad en virtud de la inclinación que ha decantado los principios básicos de la vida moral. Aunque esos principios básicos son fruto de un conocimiento universal (válido para todo tiempo y lugar), pueden ser contenidos en muy distintas reglas, costumbres y leyes. Pero todas ellas caben en esa captación primera, en ese armazón propio de la inclinación natural.

Sin embargo, parece claro que Maritain se mueve aquí en un terreno especulativo poco firme, que le obliga a navegar entre dos vientos opuestos: por un lado, el carácter universal y permanente de la ley natural; por otro, su inaplicabilidad parcial a causa de las limitaciones gnoseológicas propias del devenir histórico humano. Según Sweet, para solventar estos problemas, a Maritain sólo le quedaría la posibilidad de invocar el concurso de la razón, lo cual sería difícilmente compatible con las líneas maestras de su planteamiento epistemológico que otorga la primacía a la inclinación preconceptual (Sweet, 1998, pp. 161-162). 
También el propio Maritain es consciente de otro problema: el conocimiento de la ley natural no conlleva su obediencia. Con palabras de Adela Cortina, se trata del paso crucial de la ética pensada a la ética vivida (Cortina, 2007), para lo cual es preciso activar y promover la aplicación efectiva del catálogo de derechos, incluyendo programas educativos (McCauliff, 2009, pág. 470). En cualquier caso, es justo aquí donde entra en juego la libertad humana, que posibilita la ética y que concreta la tensión histórica en la evolución y desarrollo del hombre.

Otro punto sensible de la construcción iusnaturalista de Maritain tiene que ver con el hecho de que un enfoque estrictamente iusnaturalista - como los de Sófocles y Maritain- no pueden basarse en justificaciones teológicas o religiosas para los derechos humanos, ya que la ley natural se basa en un esfuerzo comprensivo de la naturaleza humana. Sin embargo, Maritain se basa en la teología de la persona (McCauliff, 2009, pág. 471). También Juan Manuel Burgos critica este aspecto; según este autor, el propio Maritain dice haber ido más allá que Santo Tomás al afirmar que Dios no sólo es fundamento, sino que también hace conocer la ley natural, fundando así su carácter obligatorio. Burgos critica que Maritain haya llevado la dependencia ontológica del hombre respecto a Dios en lo relativo a la ley natural también al aspecto gnoseológico, lo cual menoscaba la libertad humana. Burgos considera que sería más correcto no establecer esa dependencia gnoseológica, ya que el hombre puede conocer la ley natural sin conocer a Dios (Burgos, 2006, pág. 120). Estamos totalmente de acuerdo con este planteamiento.

La respuesta tomista-mariteniana es que la razón no sólo reconoce el pensamiento creador, sino que también ella misma es creadora en tanto que razón práctica. Entramos aquí en el dominio de la ética, que es continuadora y colaboradora con el orden divino, y que presupone la libertad. Con otras palabras, las condiciones cambiantes de la historia requieren del ser humano la «invención del orden» por un esfuerzo de razón y de voluntad.

Además, para Maritain, la ley natural no es una mera transcripción del orden divino (como erróneamente se creía en épocas anteriores), sino que deja indeterminado un inmenso campo de actuación humana para concretar la ley natural según las cambiantes condiciones históricas y la libre iniciativa de la razón. Dicho de otro modo, y utilizando terminología aristotélica, la elaboración iusnaturalista no es ni exclusivamente una obra de physis (en el sentido de necesariedad natural) ni una obra de poiesis (en el sentido de elaboración humana), sino una conjunción armónica de ambos aspectos. Para Sweet, este planteamiento

«...es coherente con el progreso o el crecimiento en conocimiento moral del que habla Maritain. Semejante visión, si puede ser fundamentada, podría explicar cómo la ley natural puede ser universal e inmutable sin que, por ejemplo, muchos o la mayoría de sus preceptos hayan existido siempre y en todos los lugares» (Sweet, 1998, pág. 160). 
Esta visión de la ley natural, siendo flexible, pretende evitar el relativismo desde la afirmación de que la naturaleza humana no ha cambiado en lo fundamental, lo cual implica —e implicará- la inclinación de todo ser humano a los primeros principios (Sweet, 1998, pág. 160).

Como ya hemos adelantado, estos primeros principios o grandes inclinaciones de la persona humana son tres, según la Suma Teológica (Aquino, 2001, tomo II, pág. 757): conservar la vida, reproducción (ambas comunes a todos los seres vivos) e impulso a conocer la verdad de Dios y vivir en sociedad (específica del ser humano). Santo Tomás deriva de ahí preceptos primarios, de contenido muy general, y aplicaciones más concretas o preceptos secundarios (Irrizábal, 2011, pág. 15).

Del mismo modo Maritain, partiendo de su raíz iusnaturalista-tomista y basándose en la Declaración Internacional de Derechos del Hombre adoptada por el Instituto de Derecho Internacional el 12 de octubre de 1929, elabora una auténtica genealogía de los derechos humanos. Ante todo, de la ley natural se deriva la dignidad humana, que hace al hombre acreedor de ser tratado como un fin en sí mismo y no como un medio. A partir de ahí, se desgrana el resto de derechos que el autor engloba en tres categorías: de la persona como tal, de la persona cívica (política) y de la persona social (trabajo). Estos derechos se asemejan a los que recoge la Declaración de 1948, aunque sin hacer mención a las teorías subyacentes (McCauliff, 2009, pág. 467).

Desde su posicionamiento iusnaturalista, Maritain plantea que las nociones de derecho y obligación moral son correlativas; es decir, el hombre no sólo ostenta un derecho natural a cumplir su destino y a recibir todo lo necesario para ello, sino que, de algún modo, esto también constituye una auténtica obligación natural.

En conclusión, y a pesar de las críticas que hemos expresado, consideramos que la misma Declaración de 1948 y el acuerdo práctico en el que se basa avalan la elaboración iusnaturalista del filósofo parisino, que apunta a la existencia de una común inclinación en el ser humano de todos los tiempos hacia la virtud, con matices propios en cada tiempo y cultura que le confieren su carácter dinámico. Pero, al fin y al cabo, unas inclinaciones que responden a intuiciones íntimamente humanas y que se concretan en normas de conducta que no son de hoy ni de ayer, sino que viven en todos los tiempos y nadie sabe cuándo aparecieron, como expresa la Antígona de Sófocles.

Como hemos dicho, la epistemología iusnaturalista de la inclinación defendida por Maritain contiene el elemento positivo de su flexibilidad, y el negativo de su carácter difuso e inconcreto. Pero el acuerdo de 1948 y los recientes avances científicos en el estudio de los procesos cognitivos humanos dan la razón a Maritain, el primero porque apunta a la existencia de un credo axiológico comúnmente compartido, aunque sólo sea en el ámbito práctico. Los segundos, porque demuestran lo acertado de Maritain respecto a su concepción del proceso cognitivo humano de la ley natural, en el que la intuición ofrece un conocimiento inmediato y determinante, sobre el cual la razón discursiva actúa sólo en un segundo momento, de forma mediata e historizada, 
y según orientaciones filosóficas que propician la fragmentación y la división de la familia humana. La visión de Maritain sobre el papel de la intuición y su extensión desde la esfera de la virtud humana a la percepción de los principios de la ley natural e incluso al vasto ámbito del conocimiento estético es una de las más originales contribuciones del filósofo francés, y tal vez la mayor y más duradera de ellas (McCauliff, 2009, pág. 475).

Tracey Rowland considera que el mayor logro del proyecto iusnaturalista en el siglo XX ha sido la Declaración de 1948, el cual además es un claro ejemplo de lo que éste puede lograr (Rowland, 2008, pág. 376). Como afirma McCauliff, aquellos que hayan rechazado la ley natural porque creen que concierne exclusivamente a la razón y no tiene en cuenta a la persona en su conjunto, deben considerar la propuesta de Maritain como una esperanzada invitación al diálogo (McCauliff, 2009, pág. 477).

\section{Bibliografía}

Aouino, T. (2001), Summa Theologiae. Madrid, BAC.

Burgos, J. M. (2006), Para comprender a Jacques Maritain. Un ensayo histórico-crítico. Madrid, Fundación Emmanuel Mounier.

COMISIÓN TEOLÓGICA INTERNACIONAL (2009), A la recherche d'une éthique universelle: nouvelle regard sur la loi naturelle. Editrice vaticana.

Contreras AguirRe, S. A. (2009), «Sobre la naturaleza del derecho y el derecho por naturaleza. La política aristotélica ante la justicia natural», Pléyade, no 4, pp. 19-35.

Cortina, A. (2007), Ética de la razón cordial. Oviedo, Nóbel.

DenNey, R. L. «The natural law foundation of virtue ethics», edición electrónica consultada en www.ignatiusinsight.com (San Francisco University) el 30 de mayo de 2013.

González, A. M. (1998), «Derecho natural y derechos humanos: síntesis práctica y complementariedad teórica», Tópicos. Revista de Filosofía, no 15, pp. 73-98.

GonZÁLEZ, A. M. (coord.) (2008). Contemporary perspectives on natural law. Aldershot (Reino Unido), Ashgate.

HeRvadA, J. (1988), Introducción crítica al Derecho natural. Pamplona, EUNSA.

Hume, D. (1977), Tratado de la naturaleza humana. Madrid, Nacional.

IrRAZÁBAL, G. (2011), «Ley natural y diálogo intercultural. Acerca del documento de la Comisión Teológica Internacional». Veritas, n ${ }^{\circ} 24$, pp. 9-31.

Kant, I. (1977), Crítica de la razón práctica. Buenos Aires, Losada.

Maritain, J. (1942), Les droits de l'homme et la loi naturelle, en Oeuvres complètes (1986), Friburgo (Suiza) - París, Saint Paul.

MARITAIN, J. (1948), Introducción a UNESCO, Los derechos del hombre.

Maritain, J. (1950), La loi naturelle ou loi non écrit, en Oeuvres complètes (1986), Friburgo (Suiza) - París, Saint Paul.

Maritain, J. (2001), Natural law. Reflections on theory and practice. South Bend, Indiana, St. Augustine.

McCaulifF, C. M. A. (2009), «Cognition and Consensus in the Natural Law Tradition and in Neuroscience: Jacques Maritain and the Universal Declaration of Human Rights», Villanova Law Review $\mathrm{n}^{\circ}$ 54, pp. 435-478.

McCool, G. (1994), The Neo-Thomists. Milwakee, Marquette University Press. 
McIntyre, A. (2000), «Theories of Natural Law in the Culture of Advanced Modernity» en McLean, E. Common Truths: New Perspectives on Natural Law. ISI Books.

Mougel, R. (1998), «Jacques Maritain et la déclaration universelle des droits de 1948», Cahiers Maritain $\mathrm{n}^{\circ}$ 37, pp. 13-15.

NovaK, M. (1983), «Democracia y Estado», Revista de ciencia política, Universidad católica de Chile, vol. 5, n 1 , pp. 5-19.

PAPINI R. (2011), «Jacques Maritain, su pensamiento político y el humanismo cristiano hoy» en VV.AA. ¿Hacia una nueva era? Bilbao, Deusto Digital.

Parellada, R. (2010), «Filosofía y derechos humanos», Arbor, ciencia, pensamiento y cultura, $\mathrm{n}^{\circ} 745$, pp. 799-807.

Possenti, V. (2003), L'azione umana: morale, politica e Stato in Jacques Maritain. Roma, Città Nuova.

Rigobello, A. (1978), Il personalismo. Roma, Città nuova, Roma.

Rommen, H. (1950), Derecho Natural. Historia-Doctrina. México D.F., Jus.

Rowland, T. (2008), «Natural law: from neo-thomism to nupcial mysticism», Communio $\mathrm{n}^{\circ} 35$, pp. 374-396.

Seydoux, R. (1984), «Jacques Maritain à Mexico», Cahiers Maritain n 10, pp. 25-28.

Souella, A. (1975), «¿Por qué vuelve a hablarse de Derecho Natural?», Revista Chilena de Derecho, vol. 22, $\mathrm{n}^{\circ} 1$, pp. 79-89.

SweEt, W. (1998), «Persons, precepts and natural law», Études maritainiennes $\mathrm{n}^{\circ}$ 14, pp. 141-165.

Viотто, P. (2010), «Dalla cristianità istituzionalizzata alla città dell'uomo», Notes et documents $\mathrm{n}^{\circ} 16$, pp. 25-38.

Wechsung, F. G. (2003), «La ley natural. Respuesta de Santo Tomás a una problemática actual». Congreso Tomista Internacional, Pontificia Accademia di San Tomasso, Roma.

Universidad Loyola Andalucía

Manuel López-Casquete de Prado mlopez@uloyola.es

955-641600, ext. 460

[Artículo aprobado para publicación en diciembre de 2015] 